\title{
Construindo a gestão escolar colaborativa: a experiência de um grupo de gestores ${ }^{1}$
}

Alexsandro Santos* Hivy Damasio Araújo Mello** Joana Buarque de Gusmão***

*(Câmara Municipal de São Paulo, São Paulo, SP)

**(Cenpec, São Paulo, SP) *** (Cenpec, São Paulo, SP)
Resumo: Este artigo apresenta e analisa a experiência do Grupo de Trabalho Gestão Escolar Colaborativa. 0 grupo, integrado por diretores e coordenadores de escolas públicas da zona leste do município de São Paulo, tem empreendido um esforço de compartilhamento de ações e de conhecimento sobre gestão escolar em territórios vulneráveis. A partir da compreensão da dinâmica histórica de constituição e consolidação do coletivo, busca-se apreender os traços que caracterizam a natureza colaborativa do grupo. 0 artigo também propõe uma conceituação inicial de gestão colaborativa.

Palavras-chave: Gestão colaborativa. Gestão escolar. Participação. Territórios de alta vulnerabilidade social. Desigualdades socioespaciais e educação.

Os autores agradecem às leituras e contribuições ao artigo de Antônio Augusto Gomes Batista, Vanda Mendes Ribeiro e Paula Kasmirski. Complementarmente agradecem também aos demais autores do texto utilizado como base para a análise aqui realizada (CENPEC, 2015), a saber: Thabita Aline Biazon Lopes, Guilherme Zanelato Correa e Vanda Mendes Ribeiro, que contribuíam com a elaboração do próprio texto de sistematização, levantaram bibliografias e dados, realizaram entrevistas e, ao lado de Joyce de Franco Alcântara, acompanharam as reuniões do GT no período de 2013 e 2014. Finalmente, agradecemos aos próprios participantes do Grupo de Trabalho Gestão Escolar Colaborativa, em especial Maria Claudia Fernandes, Solange Oliveira Ferreira, Solange Seno, Douglas Franco de Sá e Josafá Rehem, sem os quais todo este trabalho não seria possível. 
Desde 2013, o Grupo de Trabalho (GT) Gestão Escolar Colaborativa se reúne regularmente para discutir e promover ações na busca de uma gestão escolar pautada pela cooperação entre escolas situadas num mesmo território território este, no caso, marcado pela alta vulnerabilidade social. Composto por diretores e coordenadores pedagógicos² de escolas públicas ligadas à Diretoria Regional de Educação (DRE) ${ }^{3}$ de São Miguel Paulista (ver mais à frente), o grupo tem sua origem em um conjunto de iniciativas e discussões realizadas na zona leste do município de São Paulo a partir de 2008.

O objetivo deste artigo é apresentar e analisar a experiência do grupo que, apesar de relativamente recente, possui uma perspectiva que nos parece inovadora no que se refere à concepção de gestão escolar. Partiu-se de um trabalho de sistematização realizado pelo Centro de Estudos e Pesquisas em Educação, Cultura e Ação Comunitária (Cenpec), fruto da parceria entre essa instituição e os educadores envolvidos no GT Gestão Escolar Colaborativa. A sistematização consistiu, sobretudo, em um esforço de descrição compreensiva e de análise de uma dinâmica ainda em processo, realizado a partir de relatos e documentos coletados e/ou disponibilizados por integrantes do grupo ou pelo Cenpec, que vem acompanhando o grupo desde a sua origem (CENPEC, 2015). A sistematização cobre as atividades desenvolvidas pelo grupo entre 2013 e 2014.

O artigo está dividido em seis partes. Inicialmente, resgatamos as origens e as principais motivações da experiência, buscando situar os elementos do contexto local que possibilitaram a mobilização dos agentes em torno da temática da gestão colaborativa. A segunda parte foca na descrição dos passos seguintes do grupo, que passa a funcionar de forma autônoma. Ressaltamos os objetivos, as ações e as temáticas eleitas como prioritárias na trajetória de constituição do grupo.

Em seguida, apresentamos uma análise da experiência do GT Gestão Escolar Colaborativa, em que destacamos alguns aspectos ou valores que parecem mobilizar o seu trabalho, salientando traços do seu caráter colaborativo e especificidades ligadas ao modo de atuação almejado por esses gestores escolares em territórios de alta vulnerabilidade social.

Embora formado sobretudo por diretores e coordenadores pedagógicos, o grupo conta também, eventualmente, com a participação de outros profissionais das escolas, como secretários, assistentes, professores e até mesmo funcionários de empresas terceirizadas.

3 A DRE é uma instância da Secretaria Municipal de Educação de São Paulo. 
Na quarta parte fazemos um exercício de interpretação dos sentidos que o adjetivo "colaborativa" parece ter tomado na trajetória do grupo. Ele servirá de base ao que propomos, na parte seguinte, em um diálogo teórico: uma interpretação conceitual do que seria uma "gestão colaborativa". O esforço foi investirem um conceito que captasse os processos de colaboração mobilizados no grupo, tendo em conta distintos níveis de relações (intraescolares, da escola com o seu território, bem como com outras instituições e esferas do Estado e da sociedade civil, por exemplo) que podem estimular ou dificultar processos colaborativos, influenciando o desenvolvimento institucional da escola. Considerações finais são traçadas na sexta e última parte.

\section{Origens e CONSTITUIÇÃo do GT GeStão Escolar Colaborativa}

Em 2008, um grupo de diretores e coordenadores pedagógicos de escolas públicas, pesquisadores, lideranças e representantes de organizações da sociedade civil e de órgãos públicos estaduais e municipais articularam um conjunto de discussões em torno da temática do desenvolvimento local na zona leste do município de São Paulo. As questões relativas à educação ocuparam lugar de destaque na medida em que se reconheceu sua importância na agenda de debates. Esse seria o embrião de um processo de busca de soluções compartilhadas para os desafios das atividades de gestão e de liderança educativa por escolas situadas no Jardim Helena, Vila Curuçá e Itaim Paulista - distritos que, no desenho administrativo da cidade, são abrangidos pelas Subprefeituras de São Miguel Paulista, no caso do primeiro, e Itaim Paulista, no caso dos dois últimos - e que culminaria, alguns anos depois, na constituição do GT Gestão Escolar Colaborativa .

A Lei 13.399/2002, promulgada pela então prefeita da cidade de São Paulo, Marta Suplicy, reorganizou a administração municipal e dividiu a cidade em 31 subprefeituras, responsáveis pela gestão local dos assuntos e responsabilidades da municipalidade. Cada subprefeitura é composta por um ou mais distritos. Os distritos de Vila Curuçá e Itaim Paulista pertencem à Subprefeitura do Itaim Paulista, e os distritos de Vila Jacuí, Jardim Helena e São Miguel Paulista pertencem à Subprefeitura de São Miguel Paulista.Entretanto, todos os cinco distritos formam a Diretoria Regional de Educação de São Miguel Paulista, de modo que os gestores de Vila Curuçá e Itaim Paulista (SubItaim Paulista) e do Jardim Helena (Sub-São Miguel Paulista) se sentem próximos para trabalhar coletivamente. Por esse motivo utilizamos a denominação genérica, em alguns momentos do texto, "educadores" ou "escolas de São Miguel Paulista", por exemplo, remetendo a todo o grupo de escolas e gestores do GT Gestão Escolar Colaborativa. 
É importante evidenciar o nível de vulnerabilidade dos territórios em que as escolas do grupo então se encontravam. O distrito Jardim Helena tinha, em 2010, o segundo maior índice de vulnerabilidade da capital, com um IPVS médio de 4,25; os distritos Itaim Paulista e Vila Curuçá tinham, respectivamente, IPVS médio de 4,0 e 3,5. 0 indicador tem seis grupos de vulnerabilidade para áreas urbanas, indo da menor - grupo 1 de baixíssima vulnerabilidade - à maior - grupo 6 de vulnerabilidade muito alta -, englobando os chamados aglomerados subnormais urbanos, usados principalmente para favelas ${ }^{6}$.

Um IPVS de 4 indica vulnerabilidade média. No entanto, pode-se observar na Figura 1 que, apesar de o IPVS médio do Jardim Helena ser 4,2, 15\% da população do distrito mora em setores com vulnerabilidade 6 , e $21 \%$ em setores de vulnerabilidade 57 . No Itaim Paulista e na Vila Curuçá têm-se, respectivamente, $6,7 \%$ e $4,6 \%$ da população do distrito morando em setores com vulnerabilidade 6 , e $28,4 \%$ e $15,2 \%$ em setores de vulnerabilidade 5 . Sendo assim, há, nos três distritos, segmentos representativos da população localizados em setores de vulnerabilidade muito alta ou alta (no Jardim Helena mais de $36 \%$ da sua população, no Itaim Paulista cerca de $35 \%$ e mesmo na Vila Curuçá são quase 20\%).

IPVS significa Índice Paulista de Vulnerabilidade Social e é calculado pela Fundação Seade com base nos dados dos Censos Demográficos. No nível do distrito, fala-se em IPVS médio, pois o indicador é calculado para unidades territoriais menores - os setores censitários. Na região metropolitana de São Paulo, o distrito mais vulnerável (Jardim ngela) apresentou, em 2010, IPVS médio de 4,3.

6 Em Moema, por exemplo, que é o distrito de menor vulnerabilidade de São Paulo, não há pessoas vivendo em setores com esses níveis de IPVS (só em níveis 1 e 2). 


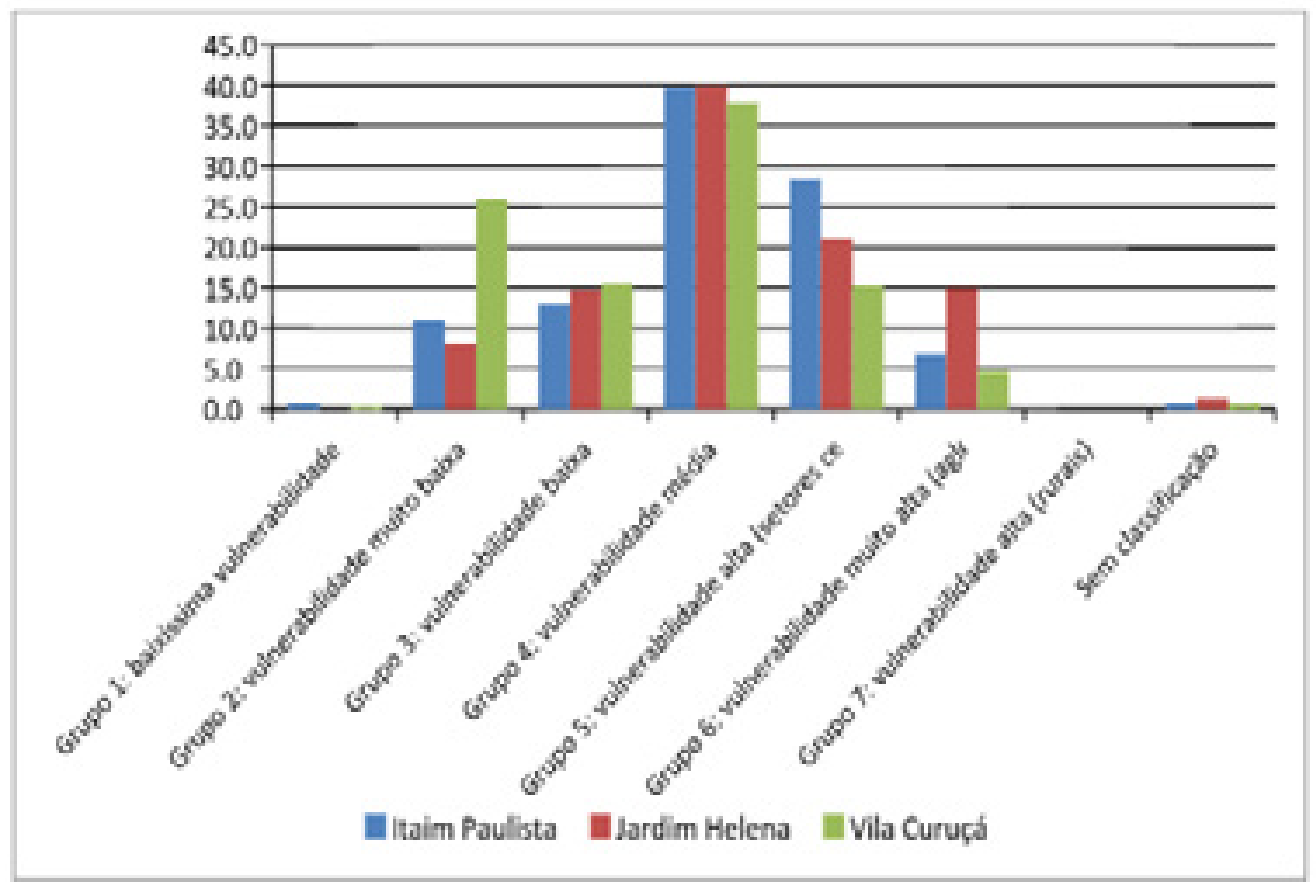

Figura 1 - IPVS do Itaim Paulista, Jardim Helena e Vila Curuçá dividido por grupos. Fonte: Elaboração própria a partir dos dados do IPVS 2010 (FUNDAÇÃO SEADE, 2015).

Gradualmente a mobilização dos gestores iniciada em 2008 foi se ampliando e conformando uma espécie de agenda comum de preocupações e temas de interesse, que aos poucos agregou ações de formação, de planejamento participativo e de integração entre os participantes. Alguns meses depois, ainda em 2008, o fortalecimento das relações de parceria e da reflexão coletiva permitiu a emergência do projeto Itaim-Curuçá - Educação como Desenvolvimento Local, composto por uma coalizão de várias organizações públicas e da sociedade civil $^{8}$.

Entre os objetivos do projeto estava o de contribuir para a articulação dos setores das diferentes políticas públicas na região, para dinamizar a economia local e para formular uma política democrática de segurança pública que combatesse a violência. Na sua base, estava a ideia de envolver

Entre eles estavam: Associação dos Moradores da Vila Aimoré, Cooperativa Mira Peripheria Digital, Escola Estadual Mário Kozel Filho (Vila Aimoré), Escola Estadual Reverendo Mattathias Gomes dos Santos (Vila Itaim), Escola Municipal de Ensino Fundamental Armando Cridey Righetti (Vila Aimoré), Escola Municipal de Ensino Fundamental Dr. José Pedro Leite Cordeiro (Jardim Cidade Kemel II), Grupo de Mulheres Solidárias Rosane Lins (Cohab Texima), Instituto Alana, Mulp-Movimento pela Urbanização e Legalização do Pantanal, e a Faculdade de Educação e a Escola de Artes, Ciências e Humanidades (ambas ligadas à Universidade de São Paulo, USP). 
as comunidades com o seu próprio desenvolvimento, de modo abrangente, no que a educação era compreendida como fator fundamental para provocar as mudanças almejadas. A escola assumiria lugar central, mas não seria 0 agente exclusivo da educação; deveria ser pensada como organização que age nos seus ambientes interno e externo, tendo como desafios definir e priorizar as suas necessidades e formas de responder a elas, agir coordenadamente, promover o desenvolvimento profissional do magistério e de outros agentes educacionais, entre outros.

Paralelamente a esse processo, nos anos de 2009 e 2010, o Cenpec começou a desenvolver na região de São Miguel Paulista a pesquisa Educação em territórios de alta vulnerabilidade social na metrópole. Seu objetivo geral era investigar se e como os territórios vulneráveis exercem, de alguma forma, influência sobre as oportunidades educacionais oferecidas pelas escolas neles localizadas; e, caso exerçam, quais são os mecanismos e processos sociais e escolares que indicam tal influência (do território sobre a escola) ${ }^{9}$.

Com tal propósito elegeu-se a região da cidade coberta pela subprefeitura de São Miguel Paulista pois, além de uma série de desvantagens socioeconômicas em relação a outras áreas da capital, apresentava uma relativa heterogeneidade socioespacial, o que permitia a abordagem das interações entre escolas e territórios com diferentes níveis de vulnerabilidade social, bem como a exploração das relações que se estabelecem entre as escolas de áreas mais vulneráveis e outras de áreas mais ricas.

De maneira sumária, a pesquisa desenvolvida pelo Cenpec concluiu que há uma relação entre o nível de vulnerabilidade do território onde se localiza a escola e as oportunidades educacionais oferecidas aos seus alunos. Isto é,

8 Compreende-se "território" como “o espaço apropriado e transformado pela atividade humana” (SANTOS, 2005). Nessa concepção, o território inclui, além da dimensão físicoespacial, "um conjunto abrangente de relações sociais, como as socioeconômicas e as políticas, bem como as representações sociais sobre ele. [...] os limites territoriais são definidos pelas pessoas e pelos grupos sociais a partir de suas representações e de suas relações" (CENPEC, 2011, p. 13). O conceito de vulnerabilidade social, pensado a partir de Katzman (2001) e da Fundação Seade (2006) como uma alternativa às formas tradicionais de caracterização e medição da pobreza (em geral acessada pela renda monetária), se referia às situações em que "agentes ou instituições não dominam um conjunto amplo de recursos socialmente produzidos que thes permitiriam fazer frente às forças e circunstâncias da sociedade que determinam suas vidas; aproveitar as estruturas de oportunidade criadas pelo mercado, Estado e pela sociedade; tomar decisões voluntárias para satisfazer suas necessidades, desenvolver suas potencialidades e realizar seus projetos" (CENPEC, 2011, p. 13). 
quanto maior o nível de vulnerabilidade social do entorno da escola, mais limitada tende a ser a qualidade das oportunidades educacionais oferecidas. Uma das evidências desse efeito pode ser verificada pelos resultados do Índice de Desenvolvimento da Educação Básica (Ideb) das escolas de São Miguel Paulista, que variam de acordo com os níveis de vulnerabilidade social do território em que as escolas estão localizadas - quanto mais as escolas estão situadas em territórios vulneráveis, menores tendem a ser suas notas no Ideb. Além disso, observou-se, em uma segunda - e mais importante - evidência: a de que crianças com um mesmo nível sociocultural têm desempenhos diferentes na Prova Brasil conforme o nível de vulnerabilidade social do local em que se situa a escola em que estudam. Isto é, quando alunos com baixos recursos culturais familiares estudam em escolas situadas nas áreas mais vulneráveis, o conjunto deles tende a ter desempenho pior na Prova Brasil do que quando alunos desse mesmo grupo estudam em escolas localizadas nas áreas menos vulneráveis. Por sua vez, alunos com maiores recursos culturais têm notas mais baixas quando estudam em escolas localizadas em territórios com alta vulnerabilidade social (CENPEC, 2011, p. 8).

A pesquisa apreendeu, também, mecanismos ou processos por meio dos quais um território vulnerável tende a restringir as oportunidades educacionais oferecidas pelas escolas nele situadas: isolamento da escola no território de alta vulnerabilidade; reduzida oferta de matrícula de educação infantil; concentração e segregação de sua população escolar em estabelecimentos de ensino nele localizados; mecanismos de interdependência competitiva entre escolas; e dificuldades, dada a posição de desvantagem nessas relações de interdependência competitiva, de apresentar as condições necessárias para garantir o funcionamento do modelo institucional que orienta a organização escolar (CENPEC, 2011).

Os resultados da investigação começaram a ser apresentados e discutidos pela equipe do Cenpec na região em 2011. Nos dois anos seguintes, as discussões sobre as conclusões da pesquisa foram mais amplamente disseminadas e apropriadas pelas pessoas envolvidas com esse debate na região, de modo que temas relacionados às especificidades do "território", bem como às questões e práticas mais propriamente escolares (ou ligadas à "gestão escolar" e, especialmente, à gestão das relações de interdependência entre as escolas localizadas num mesmo território), passaram a ser objeto de atenção de alguns gestores, sendo agregadas ao debate da anterior (com foco na educação como desenvolvimento local). 
Outra ação importante nesse período, na região, foi o curso de extensão universitária sobre "Conselhos de Escola: Educação como Desenvolvimento Local", sob a coordenação do professor Elie Ghanem, da Faculdade de Educação da Universidade de São Paulo (FE/USP). Para participar do curso, as escolas estaduais ou municipais precisaram mobilizar cinco participantes de seu Conselho de Escola e uma pessoa que exercesse liderança local na comunidade escolar.

Agregando educadores de diferentes escolas (estaduais e municipais) e fortalecendo os espaços de encontro regular entre as lideranças do território, esse curso contribuiu significativamente para a constituição do Fórum de Órgãos Públicos e Organizações da Sociedade Civil do Jardim Helena (ou Fórum de Conselhos de Escolas do Jardim Helena - Fórum Zona Leste), que, apesar de temporário, teve importante atuação entre 2011 e 2012, funcionando como uma espécie de continuidade do Curso de Conselheiros, na organização do (1ํํ) Seminário “Educação como Desenvolvimento Local”, ocorrido em $2012^{10}$.

As relações entre escolas, lideranças locais e diferentes entidades públicas ou da sociedade civil na região criaram as condições para a realização de duas edições do Seminário "Educação como Desenvolvimento Local” (2012 e 2013) ${ }^{11}$. Os dois seminários funcionaram como espaços de sistematização da reflexão e produção coletiva de conhecimento dos gestores escolares que atuavam no território desde 2008. Nesse processo, emergiu o GT Gestão Escolar Colaborativa.

O primeiro Seminário contou com a participação de cerca de 250 pessoas. Nesse encontro, ao lado de outras discussões sobre desenvolvimento local, - Cenpec apresentou e discutiu as conclusões da pesquisa Educação em territórios de alta vulnerabilidade social na metrópole (CENPEC, 2011).

Na segunda edição do Seminário, mobilizaram-se, além do Cenpec, a Diretoria Regional de Educação [Municipal] de São Miguel Paulista, a Diretoria Regional de Educação [Municipal] de Itaquera, a Diretoria de Ensino [Estadual] - Leste 2, a Faculdade de Educação e a Escola de Artes, Ciências e Humanidades da Universidade de São Paulo, o Centro de Integração da Cidadania (CIC) da Zona

9 Em 2015, essas iniciativas, iniciadas no Projeto Itaim-Curuçá, foram seguidas por mais um curso de extensão universitária denominado "Participação Social na Defesa de Direitos”, também coordenado por Elie Ghanem.

10 Houve, também, fora do período coberto pela sistematização, o 3ํ Seminário Educação como Desenvolvimento Local: Repensar Práticas e Unir Esforços, em 2015, com uma nova denominação do grupo organizador de “Comunidade Educadora da Zona Leste”. 
Leste e outras organizações da sociedade civil: Ação Educativa, Fundação Tide Setubal, Instituto Alana, Associação de Mulheres do Jardim Camargo Novo, Rede Creche e Rede Integração. Tal evento contou com a participação de aproximadamente 400 pessoas. Envolvendo temáticas diversas em torno do desenvolvimento local e da educação, os objetivos do 20 Seminário foram assim enunciados:

- Constituir pontos de vista comuns e fundamentados sobre os desafios da educação como desenvolvimento local.

- Tratar de um arco amplo de temas.

- Formular propostas de ação.

- Estabelecer compromissos das pessoas e organizações participantes em realizar as propostas de ação e multiplicar as alianças.

O seminário teve 12 eixos temáticos ${ }^{12}$, a partir dos quais se constituíram Grupos de Trabalho. O GT Gestão Escolar Colaborativa teve a participação de 19 pessoas e contou com o pesquisador Antônio Augusto Gomes Batista, do Cenpec, como especialista convidado para dialogar sobre as propostas de ação e auxiliar o grupo na definição de três prioridades para o eixo. Além de discutir o conceito de gestão colaborativa, o grupo definiu as seguintes ações para promover o desenvolvimento local do território:

- Buscar parcerias entre as escolas e os outros serviços públicos para o atendimento dos estudantes (saúde, assistência e outros encaminhamentos).

- Discutir a relação entre as escolas e as famílias dos estudantes.

- Criar estratégias comuns de trabalho entre os gestores para lidar com os problemas cotidianos das escolas.

- Melhorar os fluxos entre as escolas, sobretudo na questão da demanda/ matrícula e na questão das transferências e encaminhamentos dos alunos da educação infantil para o ensino fundamental e do ensino fundamental para o ensino médio.

- Aumentar a cobertura (vagas) para a educação infantil.

- Aprofundar a discussão sobre alfabetização e letramento.

- Discutir a questão da alocação docente e do absenteísmo.

- Discutir e encontrar caminhos para melhorar o atendimento aos adolescentes em conflito com a lei e que estão atendidos em medidas socioeducativas.

Os 12 eixos eram: transporte, escolaridade, comunicação, elaboração de políticas, economia local, segurança pública, saúde, pesquisa sobre realidade local, pessoas com deficiência, equilíbrio ambiental, convivência escolar e gestão escolar colaborativa. 
- Discutir e encontrar caminhos para melhorar o atendimento dos estudantes com deficiência, na perspectiva da inclusão.

- Discutir e encontrar caminhos para o tratamento da questão étnicoracial na escola.

- Pressionar os órgãos da gestão (DRE/DE - Diretoria de Ensino) para que criem estratégias de apoio específicas para as escolas que enfrentam maiores dificuldades.

- Pressionar os órgãos da gestão para garantir um quadro de servidores/ funcionários que atenda verdadeiramente à necessidade das escolas.

- Criar uma rede integrada de atendimento no território.

Na dinâmica do Seminário, os GTs deveriam eleger três prioridades para 0 investimento dos seus esforços. Foram selecionadas as seguintes:

- 1 - Criação do Fórum de Gestão Colaborativa da Zona Leste: grupossetores de matrícula, grupos regionais, grupos intersetoriais ${ }^{13}$.

- 2 - Formar gestores, coordenadores pedagógicos e pessoal administrativo para gestão colaborativa.

- 3 - Criar e implementar políticas intersetoriais para as escolas, especificamente para as regiões vulneráveis, com quadros de profissionais (equipe gestora/coordenadores) mais adequados à demanda (diminuição da sobrecarga administrativa/disciplina).

Definir a criação de um “fórum” como primeira prioridade, segundo educadores que participaram daquele momento ${ }^{14}$, implicou pactuar a continuidade dos momentos de diálogo e compartilhamento das ações e conhecimentos que os participantes vinham empreendendo até então. Foi elencado um conjunto de temas/problemas considerados relevantes para os próximos encontros. $A$ agenda prevista pelo grupo trazia as seguintes temáticas: a relação escolafamília; alfabetização; medidas socioeducativas; matrículas; violência fora e dentro da escola; alocação docente; absenteísmo docente; clima escolar e condições de trabalho.

No que tange à segunda prioridade, o GT compreendeu que a formação dos gestores, coordenadores e equipes das escolas é fundamental para a garantia

12 Ao final, a denominação de "fórum" acabou sendo pouco utilizada pelo grupo. Firmaramse os nomes já mencionados Grupo Gestão Colaborativa, Grupo Gestão Escolar Colaborativa ou ainda GT Gestão Colaborativa.

13 Entrevistas com Maria Claudia Fernandes (atual diretora da Escola Municipal de Educação Infantil - Emei - Epitácio Pessoa, então diretora da Emef Armando Cridey Righetti) e Solange Oliveira Ferreira (diretora da Emei Profạ. Laura da Conceição Pereira Quintaes), realizadas por pesquisadores colaboradores da sistematização em 19 de novembro de 2014. 
tanto de práticas colaborativas de gestão quanto de melhores condições de oferta educativa em territórios de vulnerabilidade social. Para isso, o grupo decidiu buscar a colaboração de formadores vinculados a organizações da sociedade civil (OSCS) e a universidades. Nesse momento, foi avaliada como estratégica a participação do Cenpec, no acompanhamento do GT.

Sobre a terceira prioridade, o GT compreendeu que os distritos de São Miguel Paulista, Vila Jacuí, Jardim Helena, Vila Curuçá, Itaim Paulista e Lajeado ${ }^{15}$ (distritos que então tinham participantes no grupo) estavam bastante defasados no que tange à constituição e funcionamento da rede de proteção social, o que dificultava uma efetiva colaboração entre as escolas e os demais serviços públicos da rede. A pouca articulação entre os órgãos gestores responsáveis pelas diferentes políticas públicas, além disso, prejudicava o planejamento e a implementação conjunta de ações. Para essa prioridade, o grupo entendeu que seria necessário pressionar o poder público a fim de que houvesse maior investimento de recursos financeiros e mais espaços de compartilhamento entre os profissionais das diferentes áreas que atuavam no território.

GT GestÃo Escolar Colaborativa: PRIMEIROS PASSOS DE FUnCIONAMENTO

Com essas prioridades, o GT empreendeu, nos meses seguintes de 2013 , os primeiros três encontros. 0 relato de uma das participantes é revelador da dinâmica de organização e de mobilização posterior ao segundo seminário:

\begin{abstract}
A partir dessa espécie de agenda temática tirada do seminário, a condição sine qua non para a realização de todos os seus apontamentos seria a continuação do GT fora do espaço do seminário, com certa periodicidade e abertura para mais gestores [...]. Nesse sentido, ficaram acordados para os meses seguintes novos encontros desse grupo sobre gestão colaborativa. A adesão para a participação desse grupo foi um pouco menor em relação ao [primeiro] encontro no [2o] seminário [...]. O intuito das reuniões eram a divulgação e o amadurecimento da ideia da primeira proposta [Criação do Fórum/GT de Gestão Colaborativa]. As reuniões, então, tinham como objetivos: aglutinação de gestores, exploração de novas ideias e de como organizar o Fórum (ainda também chamado de Grupo de Trabalho), de sua maneira de atuação, se haveria apoios externos e quais temáticas inicialmente o Fórum abordaria tendo como referência aquela lista de temas originada no Seminário (FERNANDES, 2014).
\end{abstract}

No relato da mesma diretora do depoimento acima, nesse momento de encaminhar o funcionamento do grupo, os participantes compreenderam ser importante a atuação do Cenpec como parceiro fomentador e mediador das

${ }_{14}$ A essa altura, após o “Curso sobre Conselhos de Escola: Educação como Desenvolvimento Local”, o distrito de Lajeado tinha escolas representadas no grupo. 
discussões. Havia a expectativa de que essa instituição pudesse favorecer a construção da metodologia de trabalho a partir de sua experiência e conhecimento:

A partir da atuação mais participante desses seis gestores assíduos nos encontros, foi sugerida uma organização das reuniões para o ano seguinte [2014] que teria como tarefa inicial a elaboração de uma proposta de trabalho, envolvendo aprendizado, periodicidade e algum tipo de produto teórico que pudesse auxiliá-los. Dessa forma, foi solicitado ao Cenpec, que já atuava como parceiro, a tarefa de auxiliar na organização das reuniões, atuando no papel de mediador, e com a participação de especialistas, caso fosse necessário, para o andamento das tarefas solicitadas em reunião. Ficou também acordado

que o Cenpec, como organização externa, poderia sugerir uma metodologia de trabalho para que fosse discutida posteriormente e definida em conjunto com o grupo (FERNANDES,

No primeiro encontro do grupo em 2014 foram discutidas a metodologia de trabalho a ser adotada ao longo do ano e uma agenda, chegando a um acordo sobre a dinâmica de trabalho para as reuniões seguintes, tal como descrito abaixo.

Aspectos gerais:

- As reuniões se desenrolariam em torno das temáticas elencadas pelos gestores componentes do GT. Essas temáticas poderiam ser revistas durante o processo.

- Haveria um sistematizador do Cenpec que acompanharia todas as reuniões. A sistematização envolveria os limites, os desafios e as potencialidades da gestão escolar colaborativa.

- Esse tema deveria perpassar todas as discussões, e deveria haver sempre uma preocupação com soluções práticas para o território de São Miguel Paulista.

- As discussões poderiam subsidiar o diálogo com o poder público.

Responsabilidades dos gestores:

- Apresentação de relatos de experiências sobre as temáticas eleitas para discussão.

- Apresentação de reflexões sobre a prática a partir do diálogo empreendido no grupo.

- Leitura e discussão de textos propostos.

- Em alguns casos, apresentação inicial e exploração da temática do encontro.

Responsabilidades do Cenpec:

- Colaboração com a coordenação do grupo na organização da discussão, 
apresentando subsídios tanto para a apresentação inicial da temática quanto para sua exploração posterior, nos relatos de prática.

- $\quad$ Sistematização dos processos vivenciados pelo grupo.

Temas para o grupo em 2014:

- Relação família-escola.

- Alfabetização.

- Medidas socioeducativas.

- Matrículas.

- Violência dentro e fora da escola.

- Alocação e absenteísmo de docentes.

O GT Gestão Escolar Colaborativa foi produzindo uma forma específica de trocar e construir saberes sobre sua experiência cotidiana. Ao mesmo tempo - tomando contato e se apropriando de experiências semelhantes -, o grupo buscava elaborar conceitualmente o que vivia.

Uma das experiências estudadas pelo grupo foram as Práticas inovadoras para a inspeção educativa (UNESCO, 2012a), programa de formação de inspetores escolares realizado durante a reforma do sistema de ensino de Angola $^{16}$. Reconhecendo, nessa experiência, alguns instrumentos de gestão importantes do ponto de vista do planejamento e da implementação colaborativa de mudanças educativas, o GT decidiu apropriar-se de algumas das metodologias utilizadas naquele país.

Com recurso a uma dinâmica denominada "Chuva de Ideias" e outra denominada "Análise do Campo de Forças", o grupo empreendeu uma análise de seu estágio de desenvolvimento e de sua atuação em agosto de 2014 . 0

15 A equipe do Cenpec realizou um levantamento da produção acadêmica sobre o tema da Gestão Colaborativa na área de Educação e, paralelamente, empreendeu uma busca de experiências já realizadas e sistematizadas que guardassem semelhança com os processos identificados no grupo de São Miguel Paulista. Foram selecionadas três experiências, dentre as quais a angolana se destacou. A proposta da formação permitiu a produção de uma nova metodologia de trabalho para a inspeção escolar baseada em um mecanismo de avaliação institucional participativa dos estabelecimentos escolares, sistematizada em coleção publicada pela Unesco (UNESCO, 2012. Ver especialmente UNESCO 2012a). 
resultado dessa dinâmica foi registrado conforme descrevemos nos quadros que seguem:

\section{ONDE O GRUPO ESTÁ?}

Fase inicial de constituição do grupo, justamente a fase mais importante.

[Necessidade de] elaboração de metas e formulação do conceito de Gestão Colaborativa.

Fase de "sedução" e agregação de novos participantes.

São quatro as unidades escolares regularmente frequentes no grupo.

Quadro 1 - Síntese das discussões do grupo sobre “onde o grupo está”.

Fonte: Grupo de Trabalho Gestão Escolar Colaborativa.

\section{ONDE O GRUPO DESEJA CHEGAR?}

Curto prazo

- Consolidar um coletivo de gestores escolares do território que atue, de fato, como rede.

- Articular esse coletivo com outras instituições e serviços que atuam no território e fortalecer, mobilizar, articular e integrar a rede de proteção social ainda incipiente.

Médio prazo

- Constituir-se como um fórum de gestores focado nas questões educacionais locais.

- Fortalecer os gestores para uma melhor atuação em rede, inclusive nas tratativas e no diálogo com os poderes públicos locais.

Longo prazo

- Tornar-se referência em Gestão Colaborativa.

PALAVRAS/EXPRESSÕES DE ORDEM E DE DIREÇÃO DAS METAS

Acreditar Ter atitude Encantar

Quadro 2 - Síntese das discussões do grupo sobre “onde o grupo deseja chegar”. Fonte: Grupo de Trabalho Gestão Escolar Colaborativa. 
FORÇAS POSITIVAS E NEGATIVAS - CONCRETIZAÇÃO DAS METAS

São forças positivas que favorecem a concretização das metas do grupo:

- O desejo de transformar e qualificar o trabalho educativo que se identifica nos gestores que já estão no grupo e de outros que podem se aproximar.

- O poder de realização de cada integrante do grupo e do grupo coeso.

- As parcerias que já estão em andamento (FE/USP, DRE de São Miguel, Cenpec).

- Olhar externo e colaboração advinda de sujeitos e instituições que se aproximam e dialogam com o grupo.

São forças negativas que criam obstáculos para a concretização das metas do grupo:

- Rotina e agenda escolar.

- Escassez de tempo de trabalho do gestor.

- Cultura escolar que não prioriza as atribuições do trabalho gestor.

- Dificuldade dos próprios gestores em valorizar seu trabalho.

- Rotatividade dos participantes.

- Invisibilidade do grupo no território.

Quadro 3 - Síntese das discussões do grupo sobre "forças positivas e negativas concretização das metas".

Fonte: Grupo de Trabalho Gestão Escolar Colaborativa. 


\section{AÇÕES DO GRUPO PARA MOBILIZAR AS FORÇAS POSITIVAS E ENFRAQUECER}

\section{AS FORÇAS NEGATIVAS}

Para mobilizar/potencializar as forças positivas:

- Convidar mais pessoas.

- Criar materiais para divulgar o grupo.

Para enfraquecer as forças negativas:

- Estabelecer um cronograma de trabalho e uma agenda de encontros mais ordenada.

- Divulgar de maneira intensiva essa agenda e esse cronograma de trabalho.

- Ter um representante de cada escola do território no grupo e, se possível, garantir que cada escola participe do encontro com duplas.

- Criar momentos de formação, mobilizando especialistas em conferências/seminários para compartilhar temas atuais.

Quadro 4 - Síntese das discussões do grupo sobre "ações do grupo para mobilizar as forças positivas e enfraquecer as forças negativas".

Fonte: Grupo de Trabalho Gestão Escolar Colaborativa.

AnÁlise dA experiênCIA do GRupo de GeStÃo Escolar Colaborativa (20132014)

Podemos apreender três aspectos relevantes da jornada do grupo que contribuem com a análise de sua experiência. 0 primeiro diz respeito ao fortalecimento da ação gestora na escola, com a ampliação das condições de liderança, de autonomia e de realização do trabalho cotidiano pela equipe escolar. Uma das expectativas do grupo é que os gestores, ao participarem desse processo de gestão colaborativa, possam ampliar seus conhecimentos, qualificar suas práticas e construir novos patamares de atuação na condução de suas unidades escolares, disseminando-os também na equipe interna.

O segundo aspecto diz respeito à constituição e consolidação de um coletivo profissional que seja reconhecido como um espaço institucional de produção de conhecimento compartilhado, de troca de experiências vivenciadas e de articulação e mobilização política capaz de incentivar e promover impactos significativos na qualidade da oferta educativa no território. 
O terceiro diz respeito à participação efetiva desse coletivo de gestores no fortalecimento, mobilização e articulação da rede de proteção social já presente, mas ainda insuficiente no território. Os gestores entendem que tal atuação é responsabilidade objetiva de seu fazer, mas encontram, ainda, condições bastante desfavoráveis para exercê-la.

A seguir são traçadas considerações sobre esses três aspectos.

$1^{0}$ aspecto - Fortalecimento da ação gestora na escola

Observou-se que o grupo mais frequente aos encontros no período de 2013 e 2014, composto de seis gestores escolares ${ }^{17}$, é reconhecido no território por sua liderança. Entretanto, o princípio que está em jogo no processo vivenciado pelo grupo é o de partilhar conhecimentos e mesmo agir para responder tanto a desafios enfrentados pelas unidades escolares, isoladamente, como pelas relações de interdependência que estabelecem por compartilharem o mesmo território. Considerando a ainda insuficiente adesão permanente de gestores de outras escolas, esse movimento ainda está por se consolidar e completar.

O grupo nasceu inspirado na discussão de problemas e temas desafiadores para as escolas, buscando compartilhar e produzir respostas contextualizadas e inovadoras para essas questões e que pudessem ser mobilizadas por diferentes gestores e profissionais, de distintas unidades. Entretanto, ao longo do período observado, foi necessário dar um passo atrás para orquestrar o funcionamento do próprio grupo, o que postergou o tratamento mais aprofundado da agenda temática pactuada no início.

Uma forte demanda por formação continuada das equipes gestoras vem emergindo no grupo. Essa demanda foi sinalizada como resposta aos anseios dos participantes mais frequentes das reuniões e como estratégia para mobilizar novos gestores. A experiência formativa com a oficina de registros, realizada pelo grupo em maio de 2014, aparece como uma possibilidade interessante no campo metodológico.

$2^{0}$ aspecto - Constituição e consolidação de uma rede de gestores

O grupo vive um processo de amadurecimento de sua dinâmica e de construção de vínculos de confiança e solidariedade profissional. Nesse sentido, ainda são iniciais as condições para a emergência de uma "rede" de gestores,

16 As escolas mais assíduas aos encontros neste período eram: Emef Armando Cridey Righetti, Emei Profá. Laura da Conceição Pereira Quintaes, Emef Prof. Fernando de Azevedo, Emei Ovídio Decroly, CEl Diret. Higino Pellegrini, Emef Padre Nildo do Amaral Junior. 
com os fluxos e vínculos sustentadores de uma colaboração mais efetiva das práticas de gestão. Porém, é boa a constatação de que esses processos parecem estar em franco desenvolvimento e aprofundamento, sobretudo se considerarmos a permanência do GT apesar das dificuldades de manter encontros regulares ${ }^{18}$. Isso sinaliza que já existem vínculos de solidariedade profissional em funcionamento.

Dialogar com a DRE de São Miguel Paulista e contar com sua ajuda na mobilização dos gestores e professores para participação no grupo ${ }^{19}$ apresentou-se uma estratégia de sucesso, embora ainda não sistemática. Investir nesse caminho parece ser uma decisão positiva. Entretanto, é muito importante que sejam compreendidas as relações entre o processo instituinte, mobilizado e articulado pelo grupo de gestores, e os processos institucionais de formação continuada e/ou mobilização no território, eventualmente promovidos e realizados pela DRE. Evidencia-se como um traço positivo o fato de que essas duas dinâmicas (a instituinte, do grupo, e a instituída, das instâncias de gestão do sistema de ensino), mesmo se aproximando, não se anularam em suas especificidades.

Evidencia-se, para o próprio GT, a importância de aprofundar e compreender melhor as questões referentes à temática das "redes" (preocupação enunciada ao longo do ano de 2014), e também questões ligadas a "redes de solidariedade profissional" e ao conceito e diferentes abordagens sobre “comunidades de aprendizagem profissional". Uma compreensão mais profunda dessas questões poderia iluminar pontos ainda frágeis no grupo, fornecendo instrumentos metodológicos para o fortalecimento de vínculos e a consolidação de fluxos de trabalho colaborativo. Não por acaso, a temática das "redes" emergiu como uma das preocupações centrais para o ano de 2015.

$3^{0}$ aspecto - Participação do grupo na articulação e fortalecimento da Rede de Proteção Social

À exceção dos momentos vivenciados nos seminários "Educação como Desenvolvimento Local" - que se mostraram importantes para o grupo -, identificamos, ao longo do período analisado, dificuldades em realizar aproximações mais significativas com os demais serviços e instituições

O que, aliás, parece estar sendo alterado em 2015, com encontros mensais.

18 A DRE de São Miguel Paulista dá suporte ao grupo especialmente por meio de cessão de local para os seus encontros mensais, no Centro de Formação (Cefor), e também pela divulgação e apoio às reuniões e seminários, quando solicitado. Não influencia ou participa diretamente das discussões ou da organização interna do grupo. 
presentes no território nas áreas de saúde, assistência e desenvolvimento social, segurança pública ou participação cidadã.

Podemos destacar que as causas dessas dificuldades não são exclusivamente internas ao movimento do grupo. Há uma variável mais estrutural, ligada à lógica da formulação e implementação das políticas públicas, uma variável mais contextual, ligada à forma por meio da qual o Estado e as políticas públicas se estabelecem em territórios de maior vulnerabilidade social, e uma variável mais específica da gestão escolar, ligada às representações e práticas mais comuns nas escolas e às demandas que parte da população tem em relação às escolas situadas em territórios de maior vulnerabilidade.

No primeiro nível, o das políticas públicas, podemos dizer que o Estado brasileiro, historicamente, se constituiu de forma bastante fragmentada e suas políticas, de maneira geral, embora às vezes formuladas numa ótica de integração, são implementadas de forma compartimentalizada. Assim, as políticas de saúde, de assistência e desenvolvimento social, de cultura, de esporte, de segurança pública ou de educação se instituem desconsiderando, muitas vezes, a interlocução necessária entre si. Esse traço se manifesta na região de São Miguel Paulista e é percebido e vivenciado pelo grupo.

No segundo nível, como já evidenciaram algumas pesquisas realizadas pelo Cenpec (CENPEC, 2011; ÉRNICA; BATISTA, 2012; BATISTA; CARVALHO SILVA, 2013), podemos dizer que as regiões e territórios de elevada vulnerabilidade social são marcados por uma escassez de serviços públicos. Essa escassez tem impacto direto na possibilidade da constituição de redes de políticas públicas. No caso específico da região de São Miguel Paulista, isso também se evidencia fortemente nos relatos e nas experiências compartilhados pelo grupo de gestores.

No terceiro nível, o das práticas de gestão escolar frequentemente mobilizadas e das representações sobre a atuação dos gestores escolares, podemos dizer que há uma compreensão bastante disseminada de que os gestores escolares e suas equipes são os responsáveis diretos por atender às demandas apresentadas socialmente pela comunidade, inclusive aquelas que, em princípio, excederiam o campo educacional. Essa compreensão é ainda mais evidente em territórios de alta vulnerabilidade social, em que parece haver maior demanda da população com relação à escola. Como principal equipamento público de referência nesses territórios, as escolas tendem a ser tomadas pelos problemas sociais dos mesmos, envoltas por uma série de situações a que os gestores buscam encontrar soluções e respostas (CENPEC, 
2011) ${ }^{20}$. Ao mesmo tempo, a formação inicial que se oferece aos estudantes de pedagogia (e futuros gestores escolares) desconsidera o tamanho e a complexidade dessa tarefa articuladora que o gestor escolar poderia cumprir. Resulta, assim, que o gestor escolar que de fato desempenha essa função está bastante distante, em termos de identidade profissional, daquele que ocupa o lugar das representações sobre seu poder de atuação e articulação.

\section{SOBRE OS SENTIDOS DO ADJETIVO “COLABORATIVA"}

A análise que pudemos traçar das vivências e processos experimentados no grupo entre 2013 e 2014 evidencia que o adjetivo "colaborativa" emerge com pelo menos três sentidos:

a) Encontro, mais ou menos regular, de um grupo de gestores para falar de suas experiências comuns e refletir sobre o trabalho que realizam em um mesmo território, com a ajuda de parceiros externos.

b) Construção de soluções coletivas que, uma vez pactuadas, podem ser utilizadas por todos em suas respectivas unidades escolares e podem se tornar um conjunto de procedimentos como referência de trabalho, de "protocolos profissionais".

c) 0 grupo externaliza sua atuação coletiva e participa, no território, do desenvolvimento de ações que extrapolam os muros da escola, seja para romper com seu isolamento, seja para atenuar as relações de interdependência competitiva.

Cada um dos três sentidos para a palavra "colaborativa" indica amadurecimento e progressiva consciência do grupo a respeito do que e para que compartilha suas ideias, ações e conhecimentos. Podemos dizer que, ao longo do período observado, as dinâmicas do grupo estiveram concentradas no primeiro sentido da colaboração, apesar de alguns esforços iniciais para viabilizar os demais, a serem aprofundados.

\footnotetext{
Como se observou na pesquisa anteriormente citada, Educação em territórios de alta vulnerabilidade social na metrópole, entre os mecanismos ou processos por meio dos quais um território vulnerável tende a restringir as oportunidades educacionais oferecidas pelas escolas nele situadas está o isolamento da escola no território. Devido à escassez de serviços públicos que possam garantir os direitos sociais nos territórios mais vulneráveis, as escolas acabam por ficar isoladas em relação a outras formas de ação do Estado sobre o território (CENPEC, 2011).
} 
$\mathrm{Na}$ busca por um conceito que possa captar os processos de cooperação mobilizados pelo GT Gestão Escolar Colaborativa, é preciso ressaltar que cada escola se constitui como um espaço específico no qual se desenvolvem relações sociais particulares e como parte de um espaço social mais amplo (o território), no qual se desenvolvem outras relações, envolvendo tanto outras escolas quanto outros agentes e instituições.

Nesta dupla dimensão, as relações intraescolares e da escola com o seu território podem se constituir de forma mais colaborativa ou de forma mais competitiva, como já demonstrou pesquisa do Cenpec, e podem desencadear processos facilitadores e/ou dificultadores do desenvolvimento da escola. Ainda que considerando que essas relações se interpenetram e que não é possível desconectar seus efeitos e dinâmicas, podemos vislumbrar esses processos competitivos ou colaborativos, facilitadores ou dificultadores do desenvolvimento institucional em cinco níveis distintos ${ }^{21}$ :

- Nível 1: relações de cooperação e colaboração que se estabelecem no plano intraescolar, entre os diferentes educadores e entre os educadores e estudantes que compartilham o cotidiano escolar (dentro ou fora da sala de aula).

- Nível 2: relações entre a escola e a comunidade, entendida como o coletivo das famílias dos estudantes e outros agentes que (con)vivem no entorno da escola.

- Nível 3: relações entre as diferentes escolas, de diferentes níveis/ modalidades e redes de ensino que compartilham um determinado território.

- Nível 4: relações entre a instituição escolar e as demais instituições do próprio Estado e da sociedade civil organizada situadas no território e que podem estabelecer maior proximidade (na constituição de redes de atendimento e garantia de direitos) ou distanciamento, atuando de maneira fragmentada no mesmo território.

- Nível 5: relações entre a instituição escolar e as estruturas hierarquicamente superiores na organização do sistema de ensino que mobilizam processos de implementação e reformulação das políticas educativas.

${ }^{20}$ Algumas dessas reflexões foram anteriormente abordadas, em versão preliminar, em Santos (2015). 
$\mathrm{Na}$ medida em que os sujeitos da ação educativa organizam momentos coletivos para elaborar suas experiências, representações e entendimentos sobre os desafios que vivenciam cotidianamente e para construir práticas/ processos de trabalho e estratégias de ação para superá-los, as relações de colaboração podem tornar-se mais frequentes. Do mesmo modo, talvez mecanismos que atenuem as relações de competição possam ser mobilizados, quando do tensionamento de umas com as outras (relações de colaboração e competição).

Como os níveis descritos não são desconectados entre si, a emergência e o fortalecimento de relações de colaboração num determinado nível interferem positivamente nos outros níveis.

O que a experiência em andamento permite afirmar é que seus agentes estão investindo na ampliação das relações de colaboração localizadas sobretudo nos níveis 2 a 4 e que, no período analisado, têm sido mais evidenciadas nos níveis 1 e 2 . Também é possível afirmar que esse investimento específico traduz seus efeitos tanto nas relações estabelecidas no território quanto no plano intraescolar.

Considerando esses aspectos e buscando uma generalização dos traços mais significativos da experiência, podemos definir a Gestão Escolar Colaborativa como um processo formativo que emerge num território comum, compartilhado por diferentes comunidades escolares, que se caracteriza:

a) pela mobilização de espaços específicos para a elaboração e compreensão coletiva dos desafios comuns da prática de gestão escolar no território;

b) pela formulação e implementação de estratégias e práticas comuns de trabalho educativo pelos agentes da ação educativa ali implicados;

c) pela criação e sistematização de conhecimentos contextualizados, mas passíveis de generalização, sobre a gestão das práticas e políticas educativas.

Em determinados momentos da trajetória do grupo os processos de elaboração e compreensão coletiva dos desafios comuns estiveram mais evidentes; em outros, tornaram-se mais expressivos os processos de formulação e implementação de estratégias de ação e em outros momentos, ainda, o grupo concentrou-se no compartilhamento de seus saberes. 
O objetivo deste artigo foi apresentar e analisar a experiência do grupo Gestão Escolar Colaborativa.

A análise desse percurso permite algumas conclusões. Primeiro, o empenho, a mobilização e a atuação dos sujeitos implicados nesse processo de compartilhamento de conhecimentos e ações no campo da gestão escolar indicam, firmemente, uma escolha intencional dos seus agentes em prol do engajamento e da luta pela melhoria constante da qualidade da oferta educativa no território.

Ao compartilhar experiências e discutir, coletivamente, os desafios e alternativas que encontram no trabalho cotidiano de gestão escolar, os integrantes do GT buscam produzir e implementar, apesar das dificuldades, inovações educativas que gerem impactos relevantes na melhoria das condições de ensino e aprendizagem de cada unidade escolar.

A movimentação e articulação do grupo no território, embora ainda em processo inicial, tem criado e ampliado conexões com outros agentes e instituições, favorecendo a emergência de redes de atendimento e garantia de direitos, que ainda precisa ser ampliada e consolidada, mas que teria potencial de envolver tanto outras instâncias do Estado quanto entidades e lideranças da sociedade civil.

Mesmo que não se restrinja a essas situações, as práticas de gestão escolar colaborativa podem ser especialmente relevantes para o enfrentamento e superação dos efeitos negativos da vulnerabilidade social dos territórios na qualidade das oportunidades educativas oferecidas às crianças, adolescentes, jovens e adultos nas escolas públicas.

Apesar de este artigo estar baseado em um processo de sistematização da experiência do grupo da sua origem até 2014, dada a data da sua publicação, vale tecer algumas considerações sobre a continuidade das atividades do GT.

Em 2015 houve encontros em todos os meses do ano, de modo que foi se consolidando um grupo mais assíduo de participantes nas reuniões. Nesse período, o grupo se estabiliza com a participação de gestores da Emei Epitácio Pessoa, da Emei Profá . Laura da Conceição Pereira Quintaes, do CEI Vila Curuçá II, do CEI Jardim Ruth e da Emef Faveira do Mato ${ }^{22}$. Com o amadurecimento

${ }^{21}$ As gestoras da Emei Epitácio Pessoa e do CEI Vila Curuçá II são participantes antigas do grupo. Antes estavam ligadas, respectivamente, à Emef Armando Cridey Righetti e à 
das discussões, ficaram mais claros os objetivos que unem os integrantes do grupo: fomentar a gestão colaborativa no território, discutir temas e problemas comuns e disseminar boas experiências. Outro ponto primordial para os participantes é refletir sobre formas de promover a equidade nas escolas, buscar aporte teórico para favorecer a reflexão e colaborar com a construção de uma rede de proteção eficaz na região. Além do debate de ideias, a intenção é favorecer mudanças efetivas nas práticas cotidianas das escolas envolvidas e influenciar políticas públicas. Tal interesse na rede de proteção social, ao que tudo indica, além de dialogar com temas de interesse na região de São Miguel Paulista, parece ter sido reforçado por uma característica marcante do grupo: o predomínio de escolas ligadas à educação infantil. Após iniciar o ano apenas com escolas ligadas à educação infantil, uma escola municipal de ensino fundamental (Emef) se juntou ao grupo, e com participação mais efetiva a partir da metade do ano.

Nesse sentido, algumas reuniões do grupo enfocam o mapeamento e reflexão sobre a rede de proteção social de São Miguel Paulista e do Itaim Paulista, como já relatado, regiões integrantes da DRE de São Miguel Paulista. Buscouse, também, perceber como as questões étnico-raciais são debatidas e trabalhadas nas escolas, apesar de, com exceção da última reunião, esse tema ter sido tratado apenas lateralmente. Esses foram os temas eleitos como prioritários para os encontros de 2015. Como pressuposto está a garantia da educação de qualidade como um direito das crianças, adolescentes e jovens da região, tendo em vista a discussão de ações no território que contribuam com esse objetivo.

Foram promovidas discussões sobre o que impulsiona a gestão colaborativa e foi tomando corpo a percepção de que, além de pensá-la por meio das relações das escolas com outras escolas e instituições do seu território, era também relevante promover relações colaborativas dentro da própria escola, de modo que uma rede de cooperação se realize envolvendo gestores, professores e funcionários. Assim, uma das ações que buscou promover a troca de experiências, a cooperação e estender a disseminação do debate realizado no grupo de gestores para os demais educadores do grupo de escolas foi o "Seminário Integrado do Grupo Gestão Colaborativa - Escolas em rede”, organizado com o apoio da DRE de São Miguel Paulista e do Cenpec, que funcionou como uma espécie de reunião pedagógica coletiva entre os educadores das cinco escolas.

Emei Ovídio Decroly. 
Por fim, podem ser apontados alguns desafios para o grupo aprofundar suas ações. O primeiro é o pouco tempo disponível dos gestores, em geral sobrecarregados com grande volume de tarefas. Isso incide em pouca disponibilidade para leitura, escrita e sistematização das atividades do grupo Gestão Escolar Colaborativa, além de dificultar, por vezes, a própria participação nas reuniões. Certa rotatividade dos gestores já participantes do GT, mas, sobretudo, a adesão permanente de diretores e coordenadores de outras escolas, como mencionado, segue sendo outra lacuna a superar. Nesse sentido, talvez seja preciso ampliar as estratégias de recrutamento e manutenção de novos participantes, avaliando-se, inclusive, a possibilidade de um maior envolvimento institucional da DRE de São Miguel Paulista e/ou de outras instituições parceiras na região. No esforço de consolidar o próprio GT, discussões que podem promover mudanças mais estruturais nas políticas e ações no território, ligadas às relações de interdependência competitiva entre escolas, aos problemas de ensino-aprendizado e às dificuldades encontradas na própria formação de gestores e docentes ainda merecem aprofundamento. 


\section{Building collaborative school management: the experience of a group of managers}

Abstract: This article presents and analyses the experience of the Work Group for Collaborative School Management. The group is formed by principals and coordinators at public schools in the East Zone of the city of São Paulo, and it has been making efforts to share actions and knowledge about school management in vulnerable areas. Based on our understanding of the dynamics of the collective's trajectory of constitution and consolidation, we seek to understand the features that characterize the group's collaborative nature. The article also puts forth an initial conceptualization of collaborative management.

Keywords: Collaborative management. School management. Participation. Areas of high social vulnerability. Socio-spatial inequalities and education. 
BATISTA, A. A. G.; CARVALHO SILVA, H. Família, escola, território vulnerável. São Paulo: Cenpec, 2013.

CENTRO DE ESTUDOS E PESQUISAS EM EDUCAÇÃO, CULTURA E AÇÃO COMUNITÁRIA (CENPEC). Educação em territórios de alta vulnerabilidade social na metrópole: Síntese das conclusões. São Paulo: 2011. Disponível em: 〈http://www.cenpec.org.br/biblioteca/educacao/producoes-cenpec/ educacao-em-territorios-de-alta-vulnerabilidade-social-na-metropoles. Acesso em: 6 fev. 2015.

- Grupo de Trabalho Gestão Escolar Colaborativa: sistematização da experiência de um grupo de gestores. São Paulo: Cenpec. 2015.

ÉRNICA, M.; BATISTA, A. A. G. A escola, a metrópole e a vizinhança vulnerável. Cadernos de Pesquisa, São Paulo, v. 42, n. 146, p. 640-666, maio-ago. 2012. FERNANDES, M. C. Percurso e experiência do GT Gestão Escolar Colaborativa em São Miguel. Relato de experiência apresentado na mesa temática “Educação como Desenvolvimento Local: Convívio e Gestão Colaborativa”, no âmbito do II Congresso de Educação: Zona Leste - Currículo, Território e Direitos Humanos, realizado entre 27 e 30 de outubro de 2014.

FUNDAÇÃO SEADE. Sistema Estadual de Análise de Dados. Índice Paulista de Vulnerabilidade Social - IPVS. 2015. Disponível em: 〈http://indices-ilp.al.sp. gov.br/view/index.php?prodCod=2>. Acesso em: 1ํ dez. 2015.

. Sistema Estadual de Análise de Dados. São Paulo em Perspectiva, v. 20, n. 1, jan./mar. 2006.

KATZMAN, R. Seducidos y abandonados: el aislamiento social de los pobres urbanos. Revista de la Cepal, Santiago do Chile, n. 75, p. 171-189, dez. 2001.

SANTOS, A. Gestão escolar colaborativa: tecendo redes, produzindo saberes. 2015. (mimeo).

UNESCO. Práticas inovadoras de inspeção educativa: Angola. Buenos Aires: Instituto Internacional de Planeamiento de la Educación - lipe/Unesco, 2012. (Coleção). Disponível em: 〈http://www.buenosaires.iipe.unesco. org/publicaciones/s-rie-pr-ticas-inovadoras-de-inspe-o-educativa-angolà. Acesso em: 10 jan. 2015. 
. Competências transversais para apoiar o fortalecimento institucional: materiais de apoio à formação em competências de inspetores da educação em Angola. Buenos Aires: Instituto Internacional de Planeamiento de la Educación - lipe/Unesco, 2012a. (Livro IV). Disponível em: 〈http://www.buenosaires. iipe.unesco.org/sites/default/files/Livro_IV.pdf). Acesso em: 10 jan. 2015.

\section{Sobre os autores:}

Alexsandro Santos é doutor em Educação pela Faculdade de Educação da Universidade de São Paulo (Feusp), colaborador do Cenpec e consultor técnico legislativo na área de Educação na Câmara Municipal de São Paulo.

alexsandrosantos1980@gmail.com

Hivy Damasio Araújo Mello é doutora em Sociologia pela Universidade Estadual de Campinas (Unicamp) e pesquisadora do Cenpec.

hivy.mello@cenpec.org.br

Joana Buarque de Gusmão é mestre em Educação pela Faculdade de Educação da Universidade de São Paulo (Feusp) e pesquisadora do Cenpec.

joana.buarque@cenpec.org.br

Recebido em: novembro de 2015.

Aprovado em: dezembro de 2015. 